International Journal of Engineering \& Technology, $7(4.5)(2018) 228-232$
International Journal of Engineering \& Technology
WPC
Website: www.sciencepubco.com/index.php/IJET
Research paper

\title{
Fabrication and Mechanical Characterization of Glass and Carbon Fibre Reinforced Composite's Used for Marine Applications
}

\author{
D.Sarath Chandra ${ }^{1, a}{ }^{*}$, Dr.K.Vijaya Kumar Reddy ${ }^{2, b}$, Dr.Omprakash Hebbal ${ }^{3, c}$ \\ $1 *$ Assistant professor,MED, VNRVJIET,Bhacupally,Kukatpally, hydrabad,Telengana,India-500090 \\ 2 Professor,MED,JNTU-Hyderabd,Telengan,India,500072 \\ 3Professor,MED,PDA College of Engineering-Kalaburagi,Karnataka,India,585102 \\ *Corresponding author E-mail: ${ }^{1}$ sarathchandra7@gmail.com, ${ }^{2}$ kvijayakumarreddy@gmail.com, ${ }^{3}$ hebbalod@ rediffmail.com
}

\begin{abstract}
The composite materials are replacing the traditional materials, because of its superior properties such as high tensile strength, low thermal expansion, high strength to weight ratio. The developments of new materials are on the anvil and are growing day by day. Fiber composites such as Glass-Fiber Reinforced Polymers (GFRP) composites and Carbon-Fiber Reinforced Composites (CFRP) became more attractive due to their better properties for marine applications. In this paper, GFRP, CFRP and Hybrid composites are developed and their mechanical properties such as Hardness, tensile strength, compression strength, impact strength, toughness are evaluated. The study used to compare the effect volumetric fraction of fibers in order to improve strength and toughness, this done by using two types of fibers E-glass and carbon \& two types of resins epoxy (AralditeLY556 and Aradur HY951) and vinyl ester. In this experimental study, we found that high tensile strength, high specific strength, hardness and low density are obtained with carbon fibre reinforced composites, but high impact strength and toughness are obtained with glass fibre reinforced composites. Finally incorporate the result and try to find alternatives composites using for marine applications and obtain the best mechanical properties
\end{abstract}

Keywords: GFRP, CFRP, Hybrid composites, fabrication of GFRP, CFRP and Hybrid composites, experimental analysis

\section{Introduction}

Ships are under constant attack, both from the elements of nature and the enemy. The vast majority of ship hulls are constructed from common carbon steels, which are obviously susceptible to corrosion, but they also create distinct thermal and electromagnetic signatures easily detectable from long distances. Nonetheless, even methods which are staples of the industry have shortfalls. First, the construction process is very labor intensive, involving the welding of thousands of steel plates. Second, all the welding creates numerous heat affected zones, resulting in areas of stress concentrations. Next, the entire structure, and especially these heat-affected zones, are highly susceptible to corrosion and reduced fatigue life. Lastly, extensive coatings are required to shield the structure from the elements. All of these factors and more ultimately translate into higher build and maintenance costs for ships. For the next generation of ships, the Navy is looking to stealthier hull technologies, specifically those which create lower magnetic, acoustic, hydrodynamic, radar, and thermal signatures. One way to accomplish this is by constructing hulls out of composite materials. Composites and Hybrid composites have many advantages over carbon steel, including a much higher strength toweight ratio, lower maintenance requirement, and an ability to be formed into complex shapes such as hulls. Composites and Hybrid composites hulls also offer a number of stealth benefits. Beyond the benefits of stealth, they also have high durability and increased fatigue life. The application of FRP composites to maritime crafts was initially driven by a need for lightweight, strong, corrosion resistant durable naval boats the high acoustic transparency of composites also resulted in their use in rodomes on ships and sonar domes on submarines.

\section{Fabrication}

\subsection{Fabrication process:}

- $\quad$ Apply PVA agent then Place fibers on bottom plate

- Apply binder mixed resin to the fiber

- Place another fiber on previous one and consolidate it and apply resin

- Place the top plate and tighten the nuts

- Curing in the oven

- $\quad$ After cured, opened the plates and sample is removed 


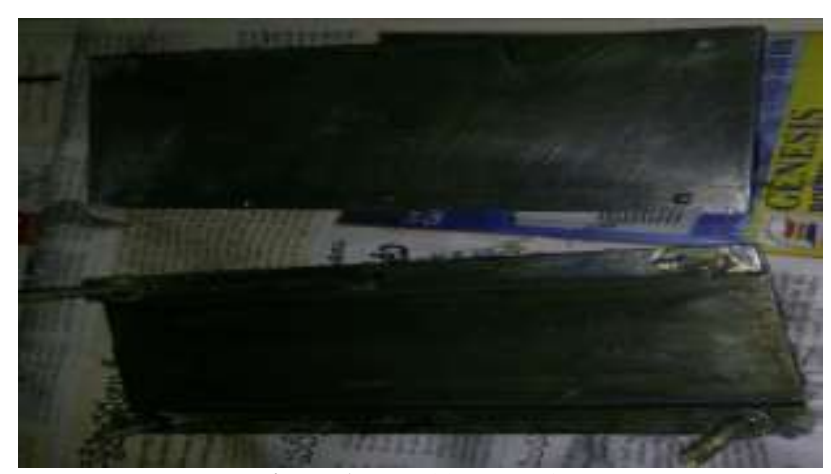

Figure 1 : Mould preparation

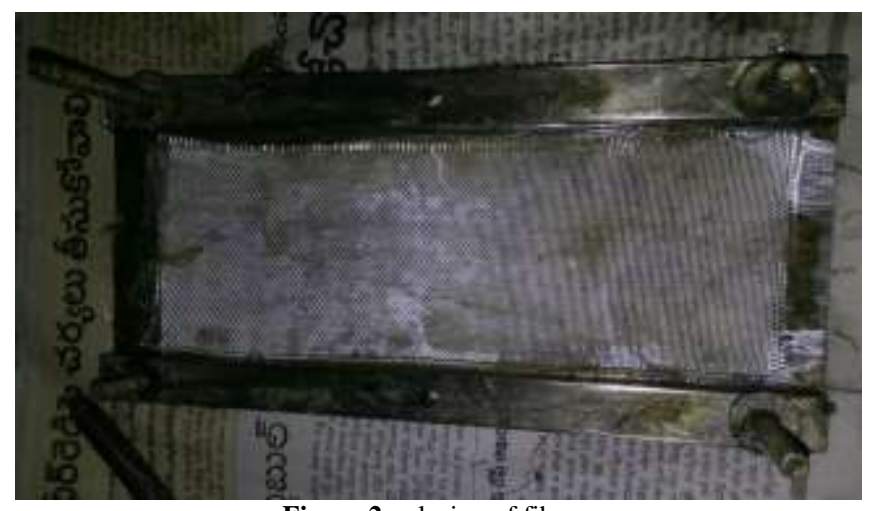

Figure 2 : placing of fibers

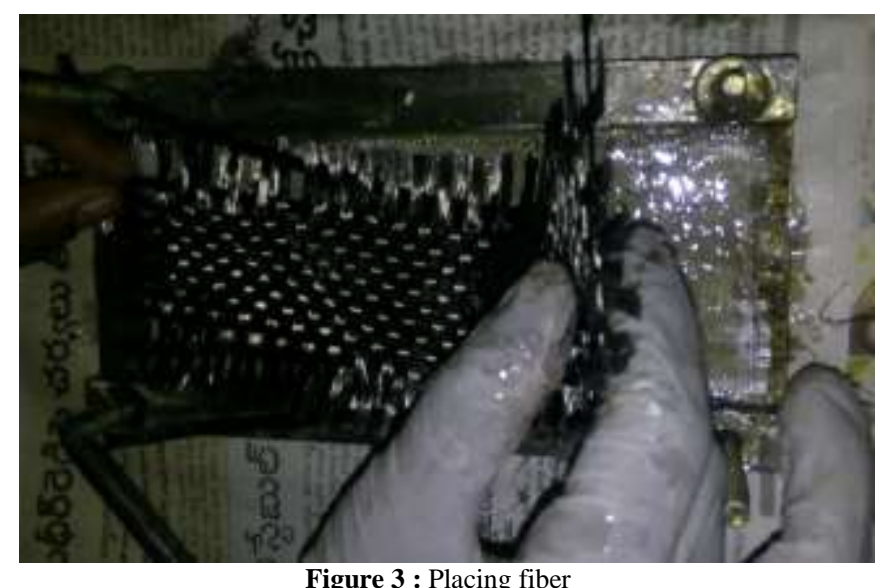

Figure 3 : Placing fiber

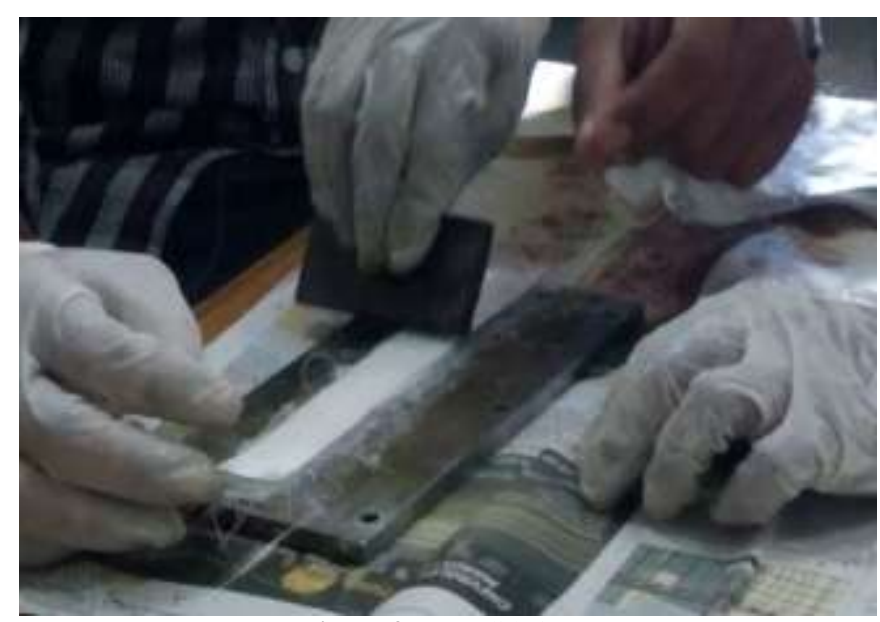

Figure 4 : consolidation

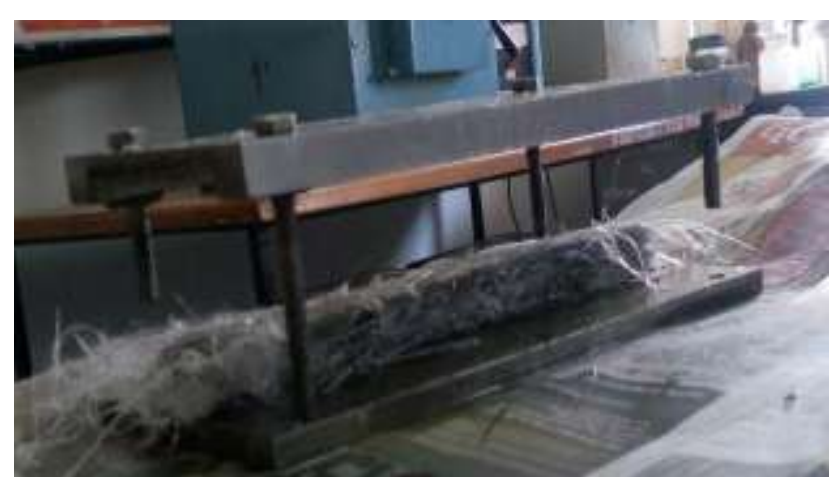

Figure 5 :placing top plate

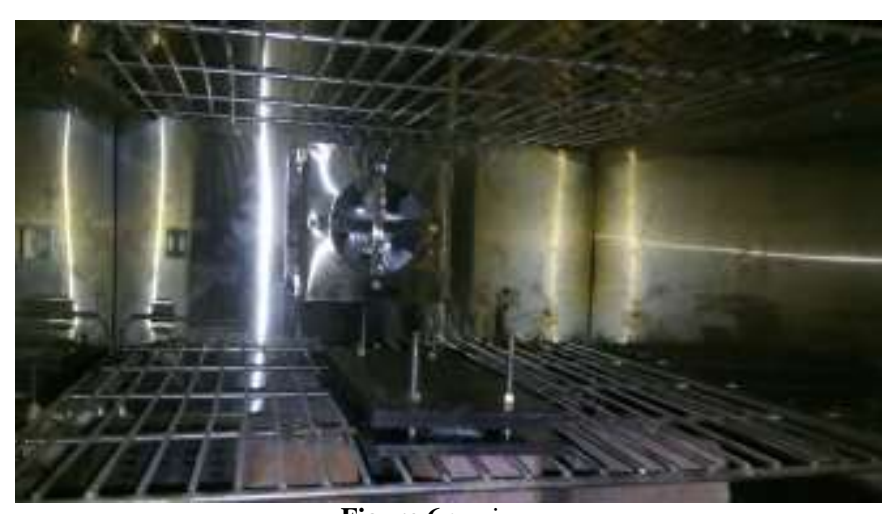

Figure 6 :curing

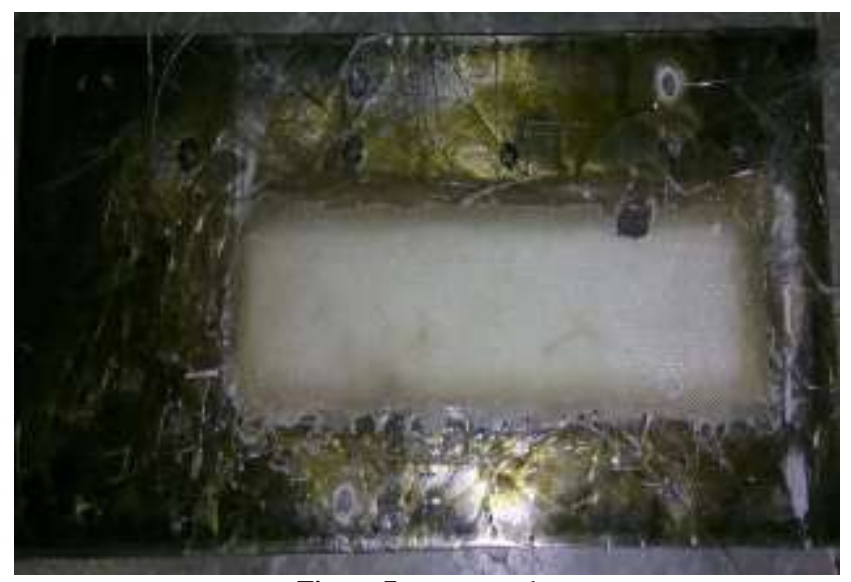

Figure 7: open top plate

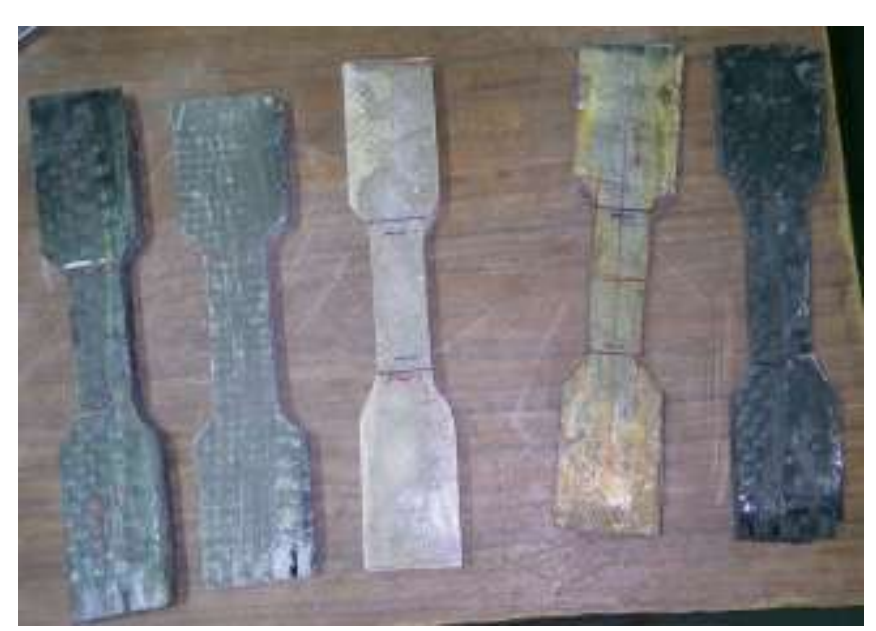

Figure 7: open top plate 


\section{Experimentation:}

\subsection{Tensile test:}

\section{Standard: ISO 527-4}

This standard is for determination of tensile properties for fiber reinforced composite which was prepared by the ISO plastics of the international organization of standardization and its dimensions is shown in the figure
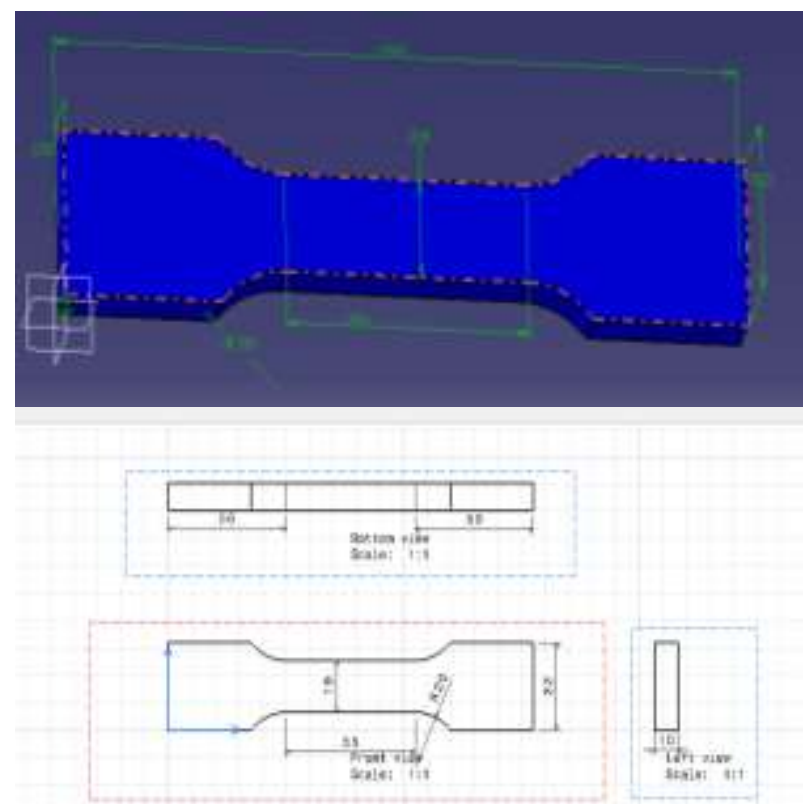

Figure 8 : Tensile Test Standard Specimen

\subsection{Impact Test:}

\section{Standard: ASTM E23}

\section{Type: IZOD Impact Test}

This standard is for determination of impact strength \& toughness for fiber reinforced composite. The test specimen is machined to a square section with one notch as shown in figure
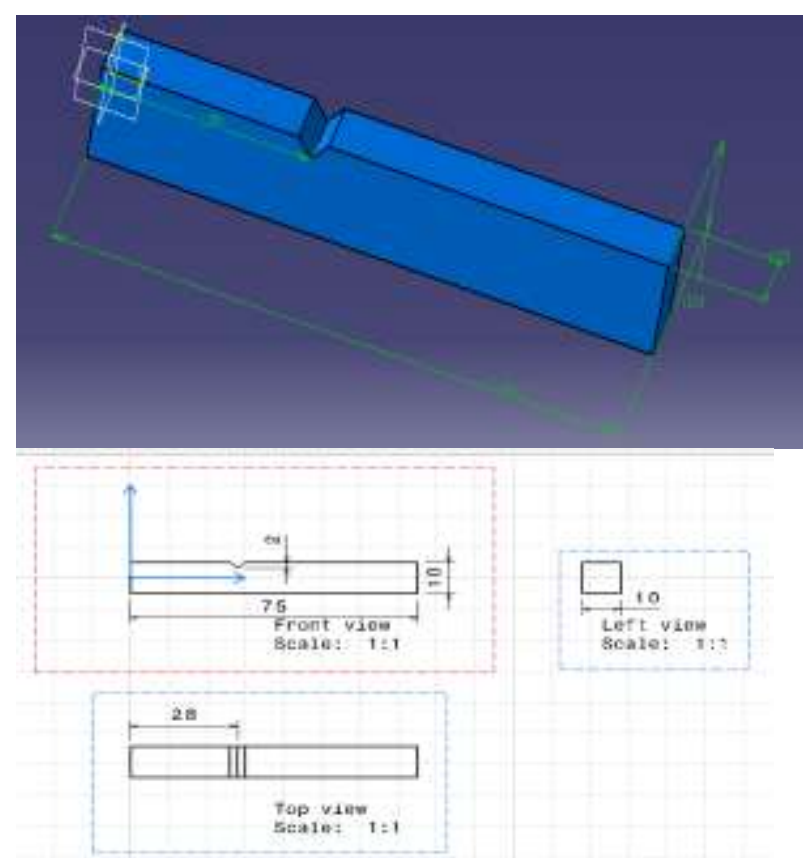

Figure 9 : Impact Test Standard Specimen

\subsection{Compressive strength:}

Standard: IS 13975

The specimen is prepared according to the dimensions shown in the figure
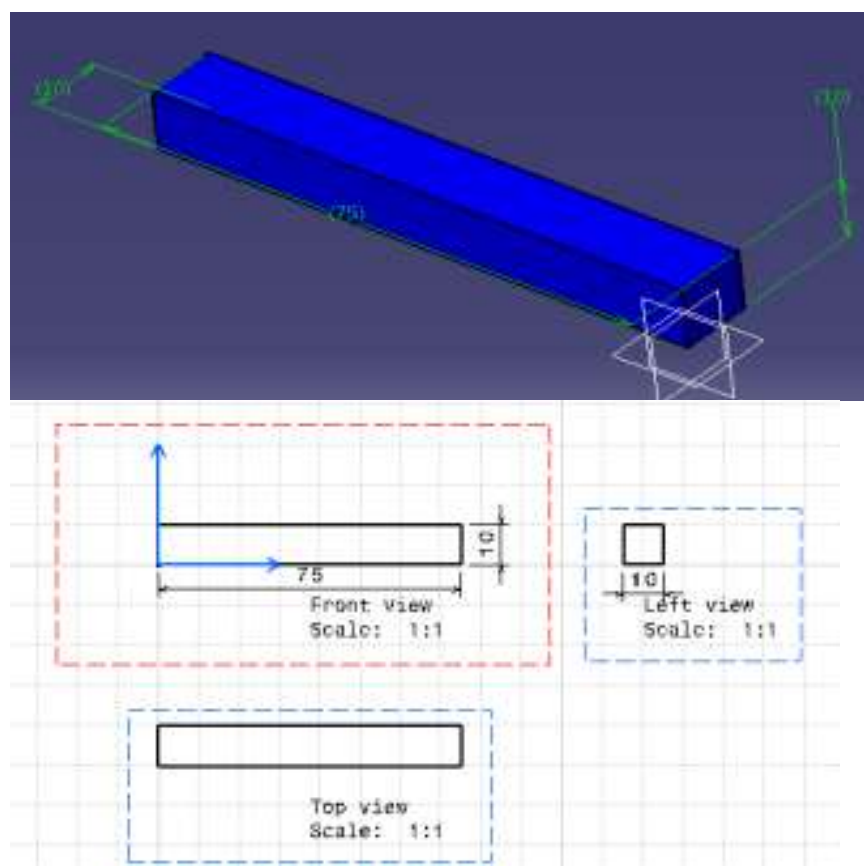

Figure 10 :Compressive Strength Test Standard Specim

\section{Theoritical analysis:}

- $\quad$ Volume of fibre $\left(\mathrm{v}_{\mathrm{f}}\right)=\mathrm{M}_{\mathrm{f}} / \rho_{\mathrm{f}}$

- Volume of matrix $\left(\mathrm{V}_{\mathrm{m}}\right)=\mathrm{M}_{\mathrm{m}} / \rho_{\mathrm{m}}$

- Volume of composite $\left(\mathrm{v}_{\mathrm{c}}\right)=\mathrm{V}_{\mathrm{f}}+\mathrm{V}_{\mathrm{m}}$

- Volumetric fraction of fiber $=\mathrm{V}_{f} / \mathrm{V}_{\mathrm{c}}$

- Volumetric fraction of Matrix $=\mathrm{V}_{\mathrm{m}} / \mathrm{V}_{\mathrm{c}}$

\section{Result and Discussions:}

Table 1::Mechanical Characteristics of GFRP and CFRP

\section{Nomenclature}

A. Mass of fibre $=\left(m_{f}\right) \quad$ B. Density of fibre $=\left(\rho_{f}\right)$

C. Volume of fibre $=\left(\mathrm{v}_{\mathrm{f}}\right)$

E. Density $=\left(\rho_{\mathrm{m}}\right)$

D. Mass of resin $=\left(\mathrm{M}_{\mathrm{m}}\right)$

$\mathrm{G}$. Volume of composite $=\left(\mathrm{v}_{\mathrm{c}}\right)$

I. Mass of E-glass fiber $=\left(\mathrm{m}_{\mathrm{gf}}\right)$

F. Volume of matrix $=(\mathrm{V})$

$\mathrm{H}$. Mass of carbon fiber $=\left(\mathrm{m}_{\mathrm{cf}}\right)$

作

M. Volume of E-glass fibre $=\left(\mathrm{V}_{\mathrm{gf}}\right) \quad \mathrm{N}$. Volumetric fraction of matrix $=\left(\mathrm{V}_{\mathrm{fm}}\right)$

\section{Graphs:}

\subsection{Comparison of Hardness:}




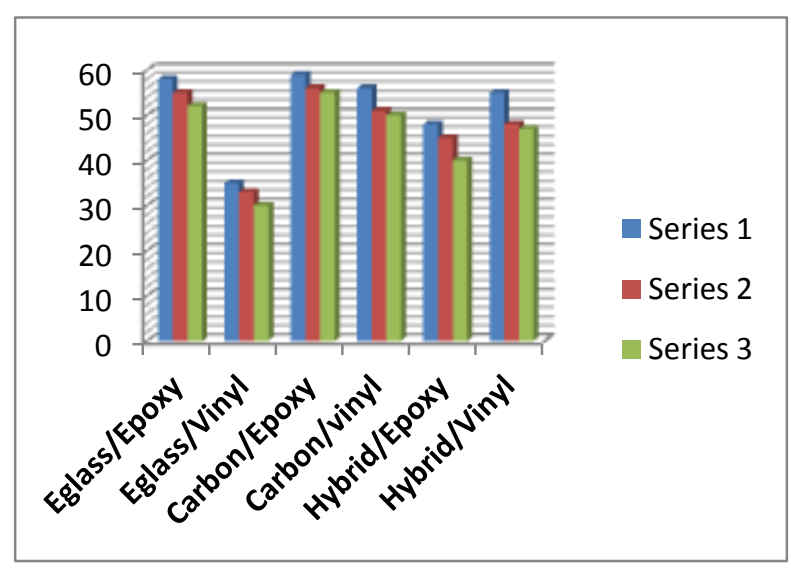

Graph 1: comparison of Rockwell hardness

\subsection{Comparison of Impact Test}

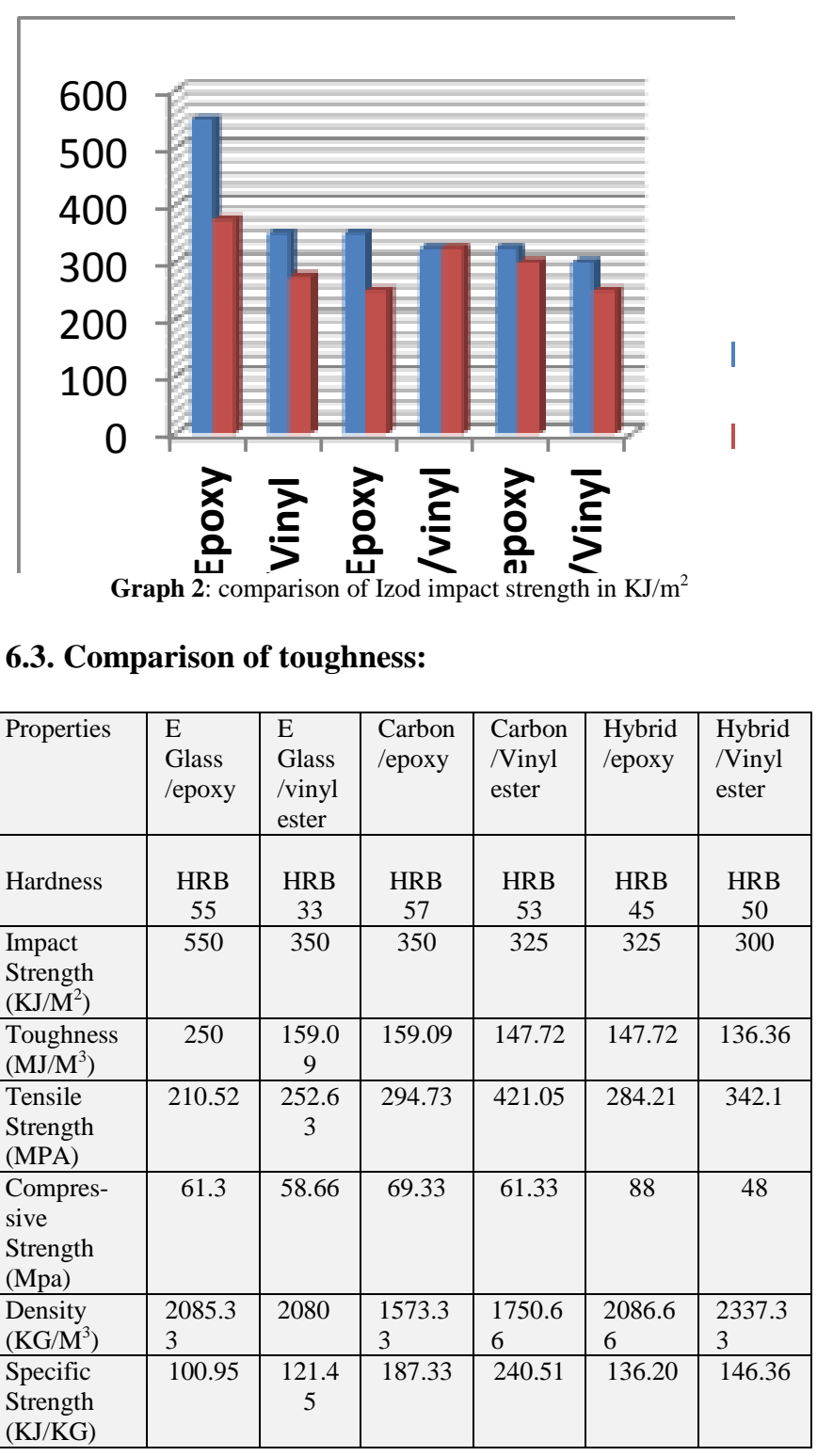

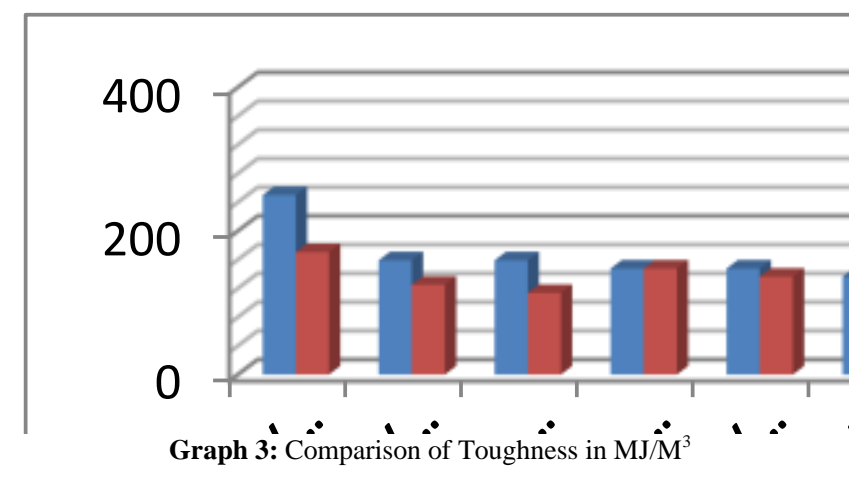

\subsection{Comparison of Tensile strength:}

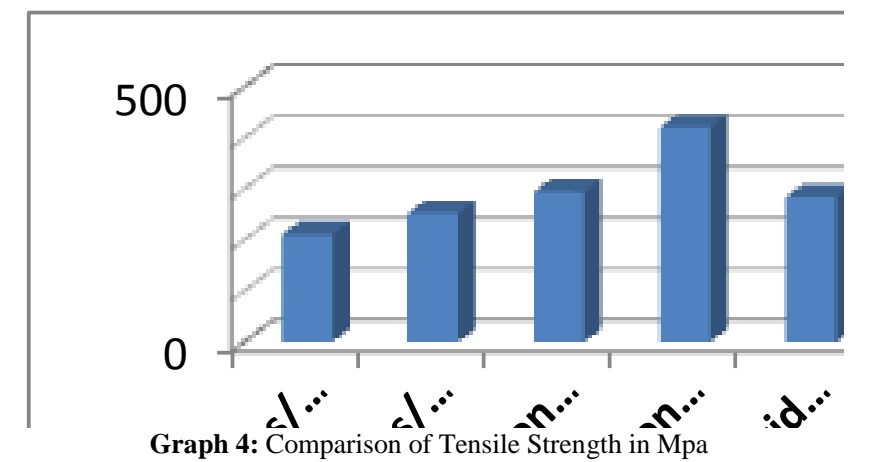

6.5.Comparison of density :

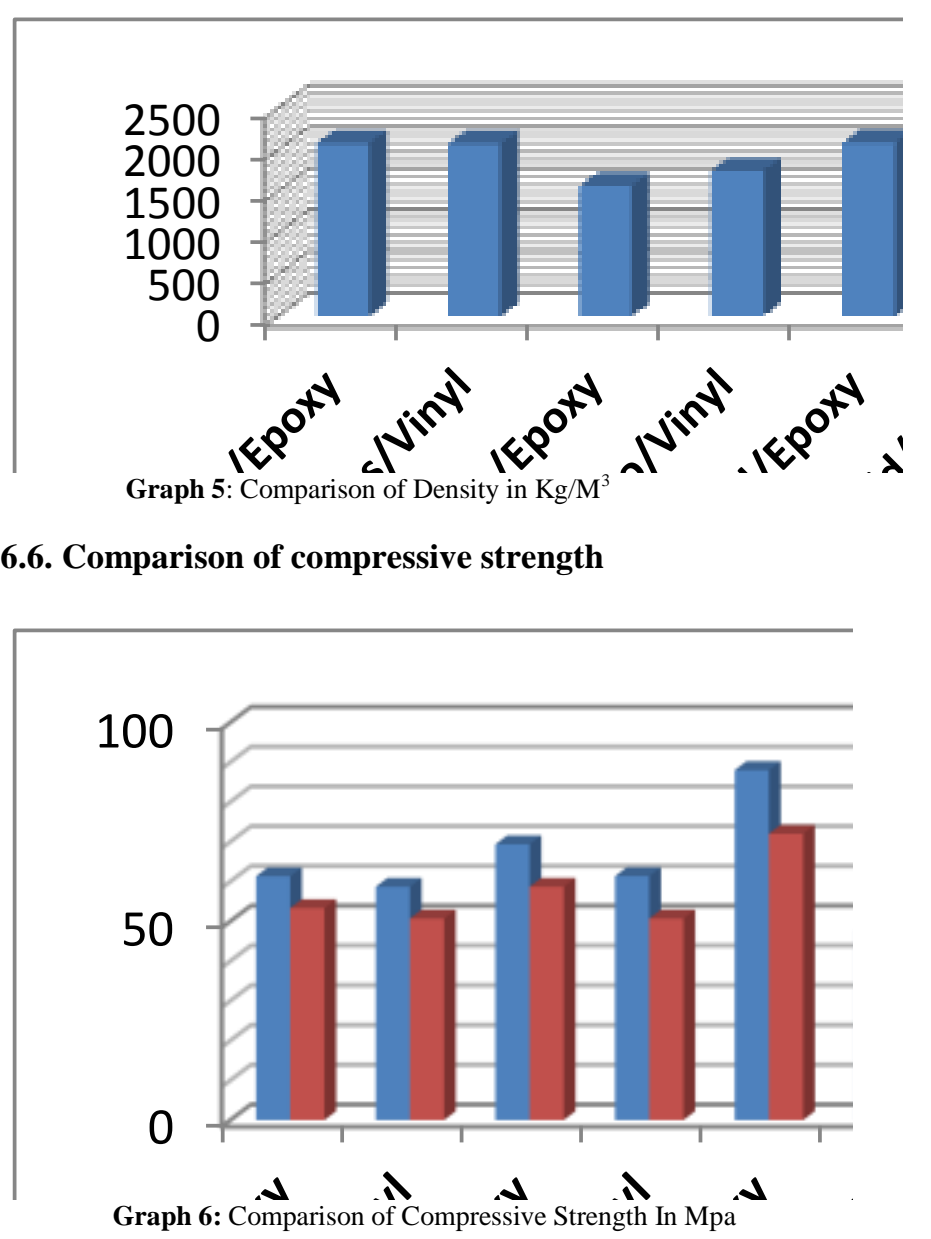




\section{Conclusion}

From the experimental investigation carried on GFRP and CFRP to observe the mechanical behavior the following conclusions are drawn

- It is clearly evident that the high tensile strength, high specific strength, hardness and low density are obtained with carbon fibre reinforced polymers but

- High impact strength and toughness are obtained with glass fibre reinforced polymers.

- The property of hybrid composite's lies between the glass and carbon fibre reinforced composite's.

- GFRP, CFRP and Hybrid composites are best suitable for marine applications .In order to reduce costs and improve properties hybrid composites are preferable .By varying the volumetric fraction, the properties can be altered for a particular application a suitable volumetric fraction can be used.

\section{References}

[1] IOSR Journal Of Mechanical And Civil Engineering (IOSR-JMCE) E- ISSN: 2278-1684 "Fabrication and Testing Of Fibre Reinforced Polymer Composites Material” By K.Alagarraja ,A.Hamodharan.

[2] International Journal Of Mining, Metallurgy \& Mechanical Engineering (IJMMME) "Effect Of Fiber Orientation For Fiber Glass Reinforced Composite Material "On Mechanical Properties By Ban.Bakir And Haithem.Hashem. ISSN 2320-4052.

[3] "Experimental Studies Of Impact On Marine Composites" By D. Choqueuse, R. Baizeau, P. Davies ,IFREMER

[4] Journal Of Engineering Research And Studies ISSN0976, “ Applications Of Composites In Marine Industry” by Dr. S. Selvaraju, S.Ilaiyavel

[5] International Journal Of Soft Computing And Engineering (IJSCE) ISSN: 2231-2307 “A Review On Recent Applications And Future prospectus Of Hybrid Composites” by Gururaja M N, A N Hari Rao

[6] Open Journal Of Composite Materials “ Production And Properties Of Short Jute And Short E-Glass Fiber Reinforced PolypropyleneBased Composites" by md Nuruzzaman Khan, Juganta K. Roy, Nousin Akter, Haydar U. Zaman, Tuhidul Islam, Ruhul A. Khan

[7] International Journal Of Engineering Research \& Technology (IJERT) ISSN: 2278-0181MECHANICAL "Characterization Of Thermoplastic Glass Fibre Reinforced Polymer Matrix Composites" by Divakar H, R Nagaraja, Puttaswamaiah S,Guruprasad H L

[8] "Mechanical Properties of Fiber Reinforced Composites Using Finite Element Method" by Sri Chandana Buddi, P Phani Prasanthi and P Srikanth ISSN $2278-0149$

[9] International Journal of Emerging Technology and Advanced EngineeringISSN 2250-2459, ISO 9001:2008 Certified Journal, "Glass FibreReinforced Polymer Composite Ceiling Fan Blade" by Amazing Comfortson S, Ahamed Faiyaz R, Mohamed Yousuf Afzal M R, Mohapilasha Nishath M.

[10] S. Mishra, A. K. Mohanty, L. T. Drzal, M. Misra, S. Parija, S. K. Nayak and S. S. Tripathy, "Studies on Mechanical Performance of Biofibre/Glass Reinforced Poly-ester Hybrid Composites," Composite Science and Technology, Vol. 63, No. 10, 2003, PP. 13771385.

[11] Jarukumjorn Kasama, Suppakarn Nitinat " Effect Of Glass Fiber Hybridization on Properties of Sisal Fiber Polypropylene Composites".:623-7.

[12] C, Sanjeevamurthy. Sisal/Coconut Coir Natural Fibers - Epoxy Composites: "Water Absorption and Mechanical Properties".International Journal of Engineering and Innovative Technology (IJEIT) Volume 2, Issue 3, September(2012).

[13] Lee. B.K. \& Jyongsik. N.R.,"Effect of moisture on the mechanical properties of glass fiber reinforced vinyl ester resin composites" Bull. Mater. Sci.,

[14] Jayabal, S., Natarajan, U. and Sathiyamurthy, S. (2011) " Effect of Glass Hybridization and Stacking Sequence on Mechanical Behaviour of Interply Coir-Glass Hybrid Laminate". Bulletin of Materials Science, 34, 293-298.
[15] M.J. Boone, V. Caccese, R. Bragg and K.A. Berube, "Mechanical Testing of Epoxy Adhesives for Naval Applications," UMMACHRPT-01-03. 